\title{
Rickettsia parkeri in Dermacentor parumapertus Ticks, Mexico
}

\section{Sokani Sánchez-Montes, ${ }^{1}$ Andrés M. López-Pérez, ${ }^{1}$ Carmen Guzmán-Cornejo, Pablo Colunga-Salas, Ingeborg Becker, Jesús Delgado-de la Mora, Jesús D. Licona-Enríquez, David Delgado-de la Mora, Sandor E. Karpathy, Christopher D. Paddock, Gerardo Suzán}

During a study to identify zoonotic pathogens in northwestern Mexico, we detected the presence of a rickettsial agent in Dermacentor parumapertus ticks from black-tailed jackrabbits (Lepus californicus). Comparison of 4 gene sequences ( $g l t A, h t r A, o m p A$, and $o m p B)$ of this agent showed $99 \%-100 \%$ identity with sequences of Rickettsia parkeri.

$R$ ickettsia parkeri is an emerging pathogen that causes a spotted fever group rickettsiosis, transmitted to humans primarily by several species of ticks of the genus $\mathrm{Am}$ blyomma, including A. maculatum, A. triste, A. tigrinum, and $A$. ovale. However, $R$. parkeri has also been detected in other hard ticks, including $A$. americanum, $A$. aureolatum, A. dubitatum, A. longirostre, A. nodosum, A. parkeri, Ixodes scapularis, Rhipicephalus sanguineus, Dermacentor parumapertus, and D. variabilis, in 8 countries in North (United States), Central (Belize), and South (Colombia, Peru, Brazil, Bolivia, Uruguay, Argentina) America $(1,2)$ (Figure 1, panel A).

Recently, a distinct strain of Rickettsia parkeri, designated $R$. parkeri Black Gap, was isolated and characterized from the tick Dermacentor parumapertus collected from black-tailed jackrabbits in Texas, USA (3). This isolate is phylogenetically related to Rickettsia sp. strain Atlantic rainforest, a well-known pathogenic lineage of $R$. parkeri associated with a mild rickettsiosis of humans in Brazil (4). In addition, the presence of R. parkeri in A. triste and

Author affiliations: Universidad Nacional Autónoma de México, Mexico City, Mexico (S. Sánchez-Montes, A.M. López-Pérez, C. Guzmán-Cornejo, P. Colunga-Salas, I. Becker, G. Suzán); Instituto Nacional de Ciencias Médicas y Nutrición Salvador Zubirán, Mexico City (J. Delgado-de la Mora); Universidad de Sonora, Sonora, Mexico (J.D. Licona-Enríquez); Instituto Tecnológico de Sonora, Sonora (D. Delgado-de la Mora); Centers for Disease Control and Prevention, Atlanta, Georgia, USA (S.E. Karpathy, C. Paddock)

DOI: https://doi.org/10.3201/eid2406.180058
A. maculatum ticks has been confirmed in several locations in Arizona $(5,6)$. Although $R$. parkeri-infected ticks have now been identified in several US states that border Mexico, no studies have demonstrated the presence of $R$. parker $i$ in ticks in Mexico.

\section{The Study}

We conducted a study to identify zoonotic pathogens in northwestern Mexico; the study area comprised a region within the Janos Biosphere Reserve in Chihuahua state $\left(30^{\circ} 51^{\prime} 50^{\prime \prime} \mathrm{N}, 108^{\circ} 30^{\prime} 09^{\prime \prime} \mathrm{W}\right)$ and in the San Pedro River Basin in Sonora state $\left(31^{\circ} 30^{\prime} 90^{\prime \prime} \mathrm{N}, 110^{\circ} 10^{\prime} 70^{\prime \prime} \mathrm{W}\right.$ ) (Figure 1, panel B). The area is in a transition zone between the Sonoran Desert, the Sierra Madre Occidental, and the Chihuahuan Desert and comprises a mosaic of grasslands, mesquite scrublands, and oak forests. During September 2013-September 2014, we sampled lagomorphs in 6 trapping locations (Chihuahuan locations: Casa de Janos, El Cuervo, Monte Verde, Pancho Villa, and Rancho El Uno; Sonoran location: Palmitas). Lagomorphs were livetrapped in box traps and leg-hold traps during a separate study to evaluate Bartonella genotypes in wild carnivores (7) under permission no. FAUT-0250 of the Secretaría de Medio Ambiente y Recursos Naturales. We identified captured animals as to species, sex, and age (juvenile or adult) using a standard field guide (8). We physically restrained the lagomorphs and visually examined them for ticks, removed the ticks manually, and deposited them in cryovials containing 96\% ethanol. We then released the hosts in situ. We performed morphological identification of ticks with specialized taxonomic keys (9).

We collected 29 ticks: 23 D. parumapertus adults from 21 black-tailed jackrabbits (Lepus californicus), 2 D. parumapertus adults from 3 white-sided jackrabbits (Lepus callotis), and 2 D. parumapertus adults and 2 Amblyomma sp. nymphs from 4 desert cottontails (Sylvilagus audubonii). We deposited 1 female and 2 male D. parumapertus ticks in the Colección del Laboratorio de Acarología, Facultad de Ciencias, Universidad Nacional Autónoma de México (UNAM) in Mexico City.

For the remaining specimens, we performed DNA extraction individually using the Chelex 100 Chelating Resin (Bio-Rad, Hercules, CA, USA) protocol (10). For the initial screening, we amplified a conserved fragment of $805 \mathrm{bp}$ of the gltA gene, which is present in all Rickettsia species

${ }^{1}$ These authors contributed equally to this article. 


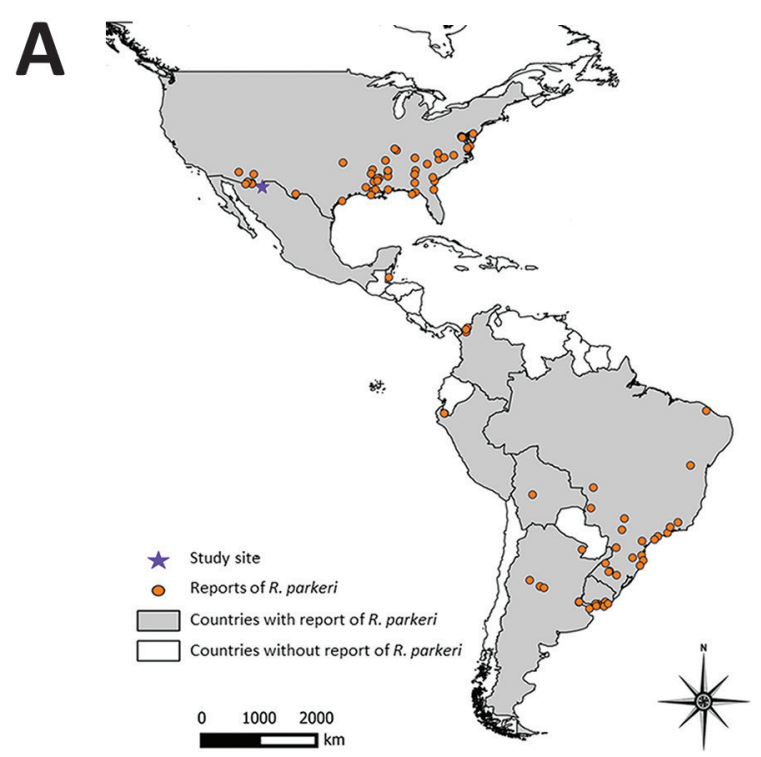

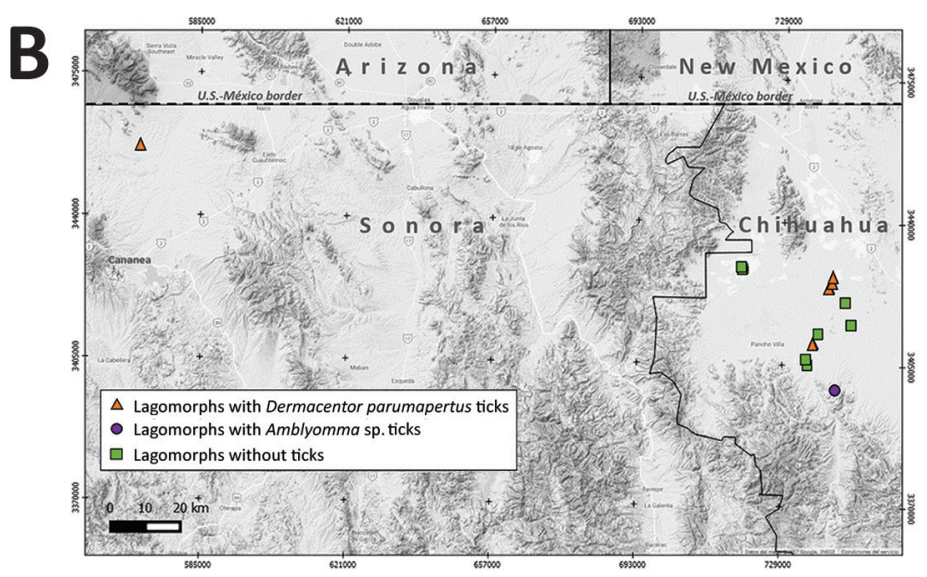

Figure 1. Distribution of Rickettsia parkeri. A) Geographic records of $R$. parkeri in the Americas based on reports from the literature. We used a layer of Google Maps (www.google.com/maps/) for the construction of the figure. B) Area of study of Rickettsia in Mexico. Squares and triangles represent the sites where lagomorphs carrying ticks were captured.
(11). We characterized all positive samples by the amplification of 3 additional gene fragments (ompA, отрB, and htrA) using primers and conditions described elsewhere $(11,12)$. The reaction mixture consisted of $12.5 \mu \mathrm{L}$ of GoTaq Green Master Mix 2X (Promega, Madison, WI, USA), the corresponding pair of primers (100 ng each), $6.5 \mu \mathrm{L}$ nuclease-free water, and $100 \mathrm{ng}$ of DNA in a final volume of $25 \mu \mathrm{L}$. In all reactions, we included a negative (reaction mix without DNA) and a positive (reaction mix with Rickettsia lusitaniae DNA detected in Ornithodoros yumatensis from a previous study in southern Mexico [11]) control. We sent amplicons of the expected size to Laboratorio de Biología Molecular y de la Salud, UNAM, for purification and sequencing. We compared the sequences obtained with those deposited in GenBank using BLAST (13). We deposited sequences recovered in this study in GenBank (accession nos. MG578509-MG578512). We performed global alignments for each gene using the ClustalW algorithm in MEGA 6.0 (https://www.megasoftware.net) and then concatenated them in BioEdit (https://www.mbio/ncsu.edu/ BioEdit/bioedit.html). We selected the nucleotide substitution model based on the lowest AICc (Akaike information criterion, corrected). We then generated a maximum likelihood phylogenetic tree with 10,000 bootstrap replications in MEGA 6.0, using the close neighbor interchange method. Gaps were excluded from the analysis.
Of the 24 D. parumapertus ticks tested, 1 female and 3 males $(16.6 \%$ total) were positive for the amplification of the gene gltA. Neither of the Amblyomma nymphal ticks was positive for Rickettsia DNA. In addition, we were able to amplify the other 3 genes in the 4 positive samples analyzed. The sequences obtained from the 4 ticks were $100 \%$ identical to each other for each corresponding gene. Comparison of 4 gene sequences exhibited $99 \%-100 \%$ identity with the corresponding sequences of $R$. parkeri (Table). The final supermatrix consisted of 2,308 bp (731 bp for gtlA, $429 \mathrm{bp}$ for ompA, $744 \mathrm{bp}$ for ompB, and $404 \mathrm{bp}$ for $h$ tr $A$ genes), with 670 variable sites, 494 singletons, and 176 parsimony informative sites. Additionally, our phylogenetic analysis corroborates the identity of the Rickettsia detected, as our sequences and those of references of the different strains of $R$. parkeri form a monophyletic clade with a support value of 98\% (Figure 2).

\section{Conclusions}

We identified DNA of $R$. parkeri in D. parumapertus ticks from Chihuahua and Sonora, nearly identical to the Black Gap strain of $R$. parkeri reported previously from $D$. parumapertus ticks from Texas. This tick species is widely distributed across much of northern Mexico, including the states of Baja California, Baja California Sur, Chiapas,

\begin{tabular}{lcc}
\hline \multicolumn{3}{l}{ Table. Results of analysis of Rickettsia sequences recovered from ticks in Mexico to Rickettsia parkeri sequences from GenBank* } \\
\hline Gene & Comparison strain (accession no.) & Sequence identity \\
\hline gltA & R. parkeri Black Gap (KY124257.1) & $731 / 731,100 \%$ \\
\hline ompA & R. parkeri RAmova (MF034495.1) & $429 / 429,100 \%$ \\
& R. parkeri Atlantic rainforest (KX137902.1) & $429 / 429,100 \%$ \\
\hline ompB & R. parkeri Black Gap (KY113111.1) & $735 / 744,98.7 \%$ \\
\hline htrA & R. parkeri (U17008.1) & $404 / 404,100 \%$ \\
\hline${ }^{*}$ Analysis conducted using BLAST (13). &
\end{tabular}




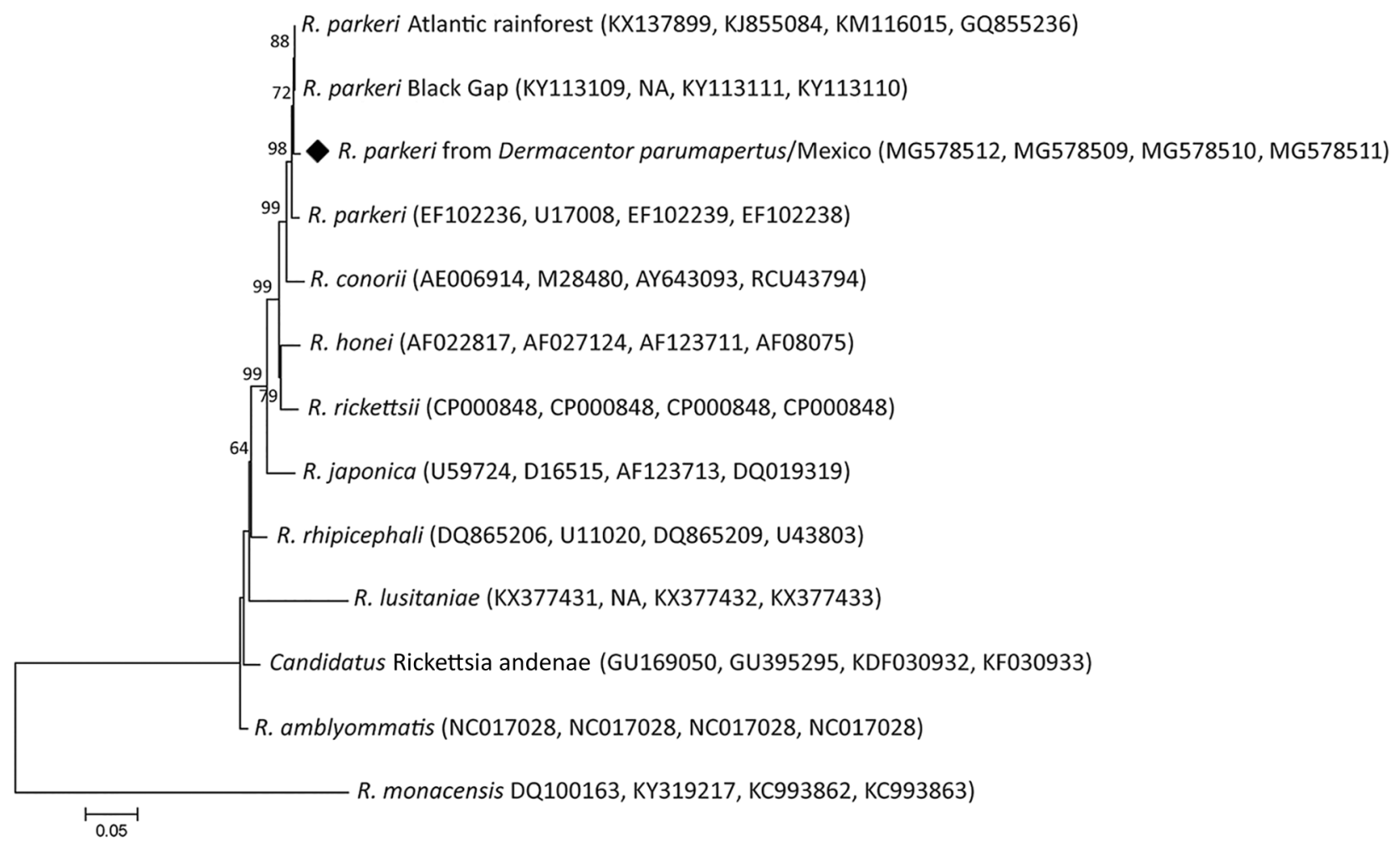

Figure 2. Maximum-likelihood phylogenetic tree generated by using the general time-reversible model using discrete gamma distribution for a total of $2,308 \mathrm{bp}$ of the gltA, htrA, ompB, and ompA genes concatenated from a few members of the genus Rickettsia. Diamond indicates isolate obtained from ticks in Mexico. Bootstrap values $>50 \%$ are indicated at the nodes $(-$ In $=-6514.38)$. Numbers in parentheses are GenBank accession numbers. Scale bar indicates nucleotide substitutions per site. NA, not available.

Chihuahua, Coahuila, Durango, Hidalgo, Mexico City, San Luis Potosi, and Sonora $(8,14)$, which suggests that this Rickettsia species could be present in other localities in Mexico. D. parumapertus ticks have a marked preference for lagomorphs; nonetheless, various other human-biting Dermacentor and Amblyomma tick species also parasitize lagomorphs, and there is a possibility that these species could acquire $R$. parkeri by co-feeding and subsequently transmit this agent to humans in these regions. The prevalence of $R$. parkeri in ticks from Mexico was consistent with other studies from Texas and Arizona, in which the prevalence ranged from $14 \%$ to $24 \%(3,5,6)$. We conducted our study in a region of Mexico where spotted fever is endemic; the incidence of spotted fever group rickettsiosis in Chihuahua in 2016 was 0.11 human cases/100,000 inhabitants and that in Sonora was 1.21 human cases/100,000 inhabitants (15). All these cases have been attributed to $R$. rickettsii, the cause of Rocky Mountain spotted fever. Although no confirmed cases of disease in humans have been attributed to $R$. parkeri Black Gap infections, previous experimental studies have shown that this isolate could be pathogenic in a guinea pig model (3). In addition, its phylogenetic relatedness with $R$. parkeri strain Atlantic rainforest, a well-recognized human pathogen (4), will have great meaning for healthcare workers in Mexico. However, further studies should be done to identify the potential of $R$. parkeri Black Gap and the strain of $R$. parkeri we identified as human pathogens. Our findings highlight the importance of studying rickettsial agents in wildlife to identify pathogens of potential public health concern.

\section{Acknowledgments}

We thank Laura Márquez for processing samples for sequencing and biologist Yokomi Nisei Lozano Sardaneta for editing our images.

This research was supported by Fundación para el Manejo y Conservación de la Vida Silvestre AC and the grants CONACyT 179482, CONACyT 221405, and PAPIIT IN217515.

\section{About the Author}

Dr. Sánchez-Montes is a biologist at the Tropical Medicine Center, Mexico City, Mexico, in charge of detecting rickettsial agents. Dr. López-Pérez is a veterinarian in the Laboratory of Disease Ecology and One Health, Mexico City, in charge of the monitoring of rickettsial pathogens in the wild. Their research interests are the identification of rickettsial agents, pathogen-host interactions, and epidemiology of zoonotic emerging diseases. 


\section{References}

1. Paddock CD, Sumner JW, Comer JA, Zaki SR, Goldsmith CS, Goddard J, et al. Rickettsia parkeri: a newly recognized cause of spotted fever rickettsiosis in the United States. Clin Infect Dis. 2004;38:805-11. http://dx.doi.org/10.1086/381894

2. Parola P, Paddock CD, Socolovschi C, Labruna MB, Mediannikov O, Kernif T, et al. Update on tick-borne rickettsioses around the world: a geographic approach. Clin Microbiol Rev. 2013;26:657-702. http://dx.doi.org/10.1128/CMR.00032-13

3. Paddock CD, Allerdice MEJ, Karpathy SE, Nicholson WL, Levin ML, Smith TC, et al. Unique strain of Rickettsia parkeri associated with the hard tick Dermacentor parumapertus Neumann in the western United States. Appl Environ Microbiol. 2017;83:e03463-16. http://dx.doi.org/10.1128/AEM.03463-16

4. Spolidorio MG, Labruna MB, Mantovani E, Brandao PE, Richtzenhain LJ, Yoshinari NH. Novel spotted fever group rickettsiosis, Brazil. Emerg Infect Dis. 2010;16:521-3. http://dx.doi.org/10.3201/eid1603.091338

5. Herrick KL, Pena SA, Yaglom HD, Layton BJ, Moors A, Loftis AD, et al. Rickettsia parkeri rickettsiosis, Arizona, USA. Emerg Infect Dis. 2016;22:780-5. http://dx.doi.org/10.3201/ eid2205.151824

6. Allerdice MEJ, Beati L, Yaglom H, Lash RR, Delgado-de la Mora J, Licona-Enriquez JD, et al. Rickettsia parkeri (Rickettsiales: Rickettsiaceae) detected in ticks of the Amblyomma maculatum (Acari: Ixodidae) group collected from multiple locations in southern Arizona. J Med Entomol. 2017;54:1743-9. http://dx.doi.org/10.1093/jme/tjx138

7. López-Pérez AM, Osikowicz L, Bai Y, Montenieri J, Rubio A, Moreno K, et al. Prevalence and phylogenetic analysis of Bartonella species of wild carnivores and their fleas in Northwestern Mexico. EcoHealth. 2017;14:116-29. http://dx.doi.org/10.1007/s10393-017-1216-2

8. Álvarez-Castañeda ST. Order Lagomorpha. In: Álvarez-Castañeda ST, Álvarez T, González-Ruiz N, editors. Keys for identifying Mexican mammals. Baltimore: John Hopkins University Press; 2017. p. 229-231.
9. Yunker CE, Keirans JE, Clifford CM, Easton ER. Dermacentor ticks (Acari: Ixodoidea: Ixodidae) of the New World: a scanning electron microscope atlas. Proc Entomol Soc Wash. 1986; 88:609-27.

10. García González LA, Rodrigo Tapia JP, Sánchez Lazo P, Ramos S, Suárez Nieto C. DNA extraction using Chelex resin for oncogenic amplification analysis in head and neck tumours [in Spanish]. Acta Otorrinolaringol Esp. 2004;55:139-44

11. Sánchez-Montes S, Guzmán-Cornejo C, Martínez-Nájera Y, Becker I, Venzal JM, Labruna MB. Rickettsia lusitaniae associated with Ornithodoros yumatensis (Acari: Argasidae) from two caves in Yucatan, Mexico. Ticks Tick Borne Dis. 2016;7:1097101. http://dx.doi.org/10.1016/j.ttbdis.2016.09.003

12. Tomassone L, Nuñez P, Ceballos LA, Gürtler RE, Kitron U, Farber M. Detection of "Candidatus Rickettsia sp. strain Argentina" and Rickettsia bellii in Amblyomma ticks (Acari: Ixodidae) from northern Argentina. Exp Appl Acarol. 2010;52:93100. http://dx.doi.org/10.1007/s10493-010-9339-y

13. Altschul SF, Gish W, Miller W, Myers EW, Lipman DJ. Basic local alignment search tool. J Mol Biol. 1990;215:403-10. http://dx.doi.org/10.1016/S0022-2836(05)80360-2

14. Guzmán-Cornejo C, Robbins RG, Guglielmone AA, Montiel-Parra G, Rivas G, Pérez TM. The Dermacentor (Acari, Ixodida, Ixodidae) of Mexico: hosts, geographical distribution and new records. ZooKeys. 2016;569:1-22. http://dx.doi.org/10.3897/zookeys.569.7221

15. Dirección General de Epidemiología (DGE). Anuarios de morbilidad durante el periodo 1995-2016 [cited 2017 Oct 10]. https://www.gob.mx/salud/acciones-y-programas/ anuarios-de-morbilidad-1984-2016

Address for correspondence: Andrés M. López-Pérez, Laboratorio de Ecología de Enfermedades y Una Salud, Departamento de Etología, Fauna Silvestre y Animales de Laboratorio, Facultad de Medicina Veterinaria y Zootecnia, Universidad Nacional Autónoma de México, Avenida Universidad 3000, Ciudad Universitaria. C. P. 04510, Ciudad de México, México; email: am.loperez81@gmail.com

\section{EID Adds Advanced Search Features for Articles}

Emerging Infectious Diseases now has an advanced search feature that makes it easier to find articles by using keywords, names of authors, and specified date ranges. You can sort and refine search results by manuscript number, volume or issue number, or article type. A quick start guide and expandable help section show you how to optimize your searches.

\section{https://wwwnc.cdc.gov/eid/AdvancedSearch}

EID's new mapping feature allows you to search for articles from specific countries by using a map or table to locate countries. You can refine search results by article type, volume and issue, and date, and bookmark your search results.

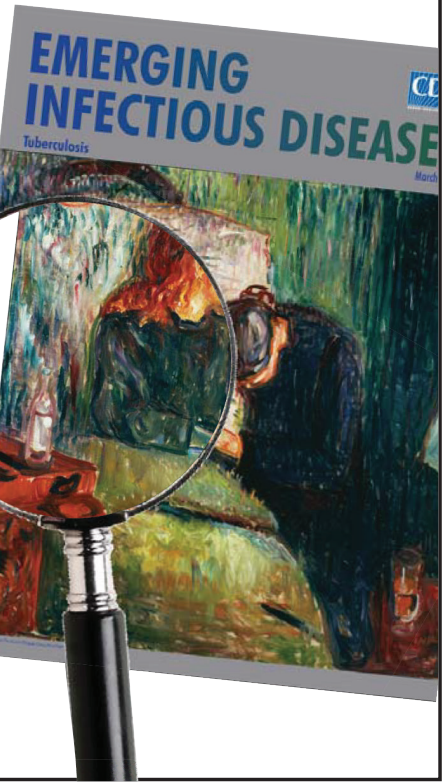

